\title{
Mutation-induced Polygenic Variability and Early Prediction of High Yielding Mutants in Greengram [Vigna radiata (L.) wilczek]
}

\author{
Tapas Ranjan Das ${ }^{1 *}$ and Bhabendra Baisakh ${ }^{2}$ \\ ${ }^{1}$ IARI Regional station, Pusa, Bihar-848125, India \\ ${ }^{2}$ Department of Plant Breeding and Genetics, OUAT, Bhubaneswar, Odisha-751 003, India \\ *Corresponding author
}

\begin{abstract}
A B S T R A C T
Three does each of gamma rays $(200,400$ and $600 \mathrm{~Gy})$, ethyl methane sulphonate $(0.2,0.4$ and $0.6 \%)$, nitrosoguanidine $(0.005,0.010$, and $0.015 \%)$, maleic hydrazide $(0.01,0.02$ and $0.03 \%$ ) and in combination were administered to the seeds of two greengram varieties, Sujata and OBGG-52. In $\mathrm{M}_{2}$ generation, population mean got decrease with increase in variance for seed yield and the magnitude of such changes varied with mutagens, their doses and the variety. Higher the dose of treatment greater the shift in mean and variance. The negative shift of mean was more pronounced in $\mathrm{MH}$ and its combined treatments in both the varieties. The $\mathrm{M}_{2}$ populations showed wider range of variations than the parent varieties. Genetic advance estimates showed that selection in many $\mathrm{M}_{2}$ treatment populations would be effective in bringing the improvement in yield/plant. Following selection among $\mathrm{M}_{2}$ plants and in $\mathrm{M}_{3}$ progenies on the basis of higher yield, ten mutant cultures in Sujata and eleven mutants in OBGG-52 were found significantly higher yield in $\mathrm{M}_{4}$ generations. Majority of them were from the groups of $\mathrm{M}_{2}$ mutagenic treatments sowing significantly higher population variance for yield/plants. Thus, selection of high yielding $\mathrm{M}_{2}$ plants in mutagenic treatments with significantly increased $\mathrm{M}_{2}$ variance for yield would be effective in isolation of high yielding micro mutant lines.
\end{abstract}

Keywords

\section{Introduction}

Pulses are the major source of dietary protein in vegetarian diets of most countries. Among the pulse crops, green gram (Vigna radiata (L.) Wilczek) is an important annual legume. It is widely grown in southeast Asia, Africa, South America and Australia. It is cultivated in tropical, subtropical, and temperate zones of Asia including Bangladesh, India, Pakistan, Myanmar, Indonesia, Philippines, Sri Lanka,
Nepal, China, Korea and Japan (Shanmugasundaram, 2001). It can be grown successfully in extreme environments (e.g., high temperatures, low rain fall, and poor soils) with few economic inputs (Das et al., 2014). This crop is utilized in several ways, where seeds, sprouts and young pods are consumed as sources of protein, amino acids, vitamins and minerals, and plant parts are used as fodder and green manure. Greengram protein is easily digested without flatulence. 
Being a legume, it has the ability to fix atmospheric nitrogen $(30-50 \mathrm{~kg} / \mathrm{ha})$ with the soil bacteria Rhizobium spp. (Dooth et al., 2017).

India is the leading greengram cultivator, with about $55 \%$ of the total world acreage and $45 \%$ of total production (Singh et al., 2013). According to the report of AICRP MULLaRP, the annual greengram production in India is around 1.5 million tonnes from about 3.02 million ha area during the year 2014-15 (Anonymous, 2016). Though India is the highest producer in the world but the productivity is comparatively low i.e. 499 $\mathrm{kg} / \mathrm{ha}$ (Directorate of Economics and statistics, 2016). One of the bottlenecks in its improvement has been the lack of variability. Induction of mutations by using physical and chemical mutagens is helpful to generate new variability. Information on the extent of induced polygenic variability or micro mutations and the genetic parameters for different polygenic traits in $\mathrm{M}_{2}$ generation gives an indication about the scope of improvement in traits through selection. In present study attempt has been made to ascertain the magnitude of induced genetic variability and the genetic parameters of yield and its components in $\mathrm{M}_{2}$ generation and its relationship in isolation of high yielding mutant progenies in $\mathrm{M}_{4}$ generations.

\section{Materials and Methods}

Dry, uniform and healthy seeds of two varieties of greeengram, namely Sujata and OBGG-52 were administered mutagenic treatments with three doses each of gamma rays (200, 400 and 600Gy), ethyl methane sulphonate (EMS) $(0.2,0.4$ and $0.6 \%)$, nitroso guanidine (NG) $(0.005,0.010$ and $0.015 \%)$ and maleic hydrazide $(\mathrm{MH})(0.01,0.02$ and $0.03 \%$ ) singly and combine mutagens of 400Gy gamma rays with $0.4 \%$ EMS or $0.010 \% \mathrm{NG}$ or $0.02 \% \mathrm{MH}$. The twelve single mutagenic treatments of gamma rays, EMS, $\mathrm{NG}$ and $\mathrm{MH}$ were coded as G1, G2, G3, E1, $\mathrm{E} 2, \mathrm{E} 3, \mathrm{~N} 1, \mathrm{~N} 2, \mathrm{~N} 3$ and $\mathrm{M} 1, \mathrm{M} 2$ and M3, respectively. Three combined treatments of 400Gy gamma rays $+0.4 \%$ EMS, 400Gy gamma rays $+0.01 \% \mathrm{NG}$ and $400 \mathrm{~Gy}$ gamma rays $+0.02 \% \mathrm{MH}$ were coded as GE2, GN2 and GM2, respectively. Dry seeds were irradiated with gamma rays treatment at Bhava Atomic Research Centre (BARC), Trombay. For treatment with EMS, NG and $\mathrm{MH}$, the seeds were presoaked in distilled water for 6 hours, blotted dry and then treated with freshly prepared aqueous solution of above chemical mutagens for 6 hours, with intermittent shaking. For combination treatments, seeds were first irradiated with $400 \mathrm{~Gy}$ gamma rays and then treated with $0.4 \%$ EMS or $0.01 \%$ NG or $0.02 \% \mathrm{MH}$ solution in the same manner as described above. After treatment, the seeds were thoroughly washed with running water to bleach out the residual chemicals and then dried on blotting paper after treatment. The $\mathrm{M}_{1}$ generation was grown with the utmost care self-pollination. Seeds from all the $\mathrm{M}_{1}$ plants of each treatment were harvested and were bulked to grow a representative bulk $\mathrm{M}_{2}$ generation for study of induced genetic variability and the genetic parameters of yield and its components. The $\mathrm{M}_{2}$ to $\mathrm{M}_{4}$ generations were raised in the EB-II section of Orissa University of Agriculture and Technology (OUAT), Bhubaneswar.

In $\mathrm{M}_{2}$ generation, two separate trials, one for each variety were laid out in RBD with three replications with spacing of $25 \times 10 \mathrm{~cm}$. Twenty normal looking plants, excluding the macro-mutants were randomly chosen from each plot and observations were recorded on seed yield/plant $(\mathrm{g})$. Mean and variance of the trait in each treatment population were estimated and subjected to statistical analysis. The genetic parameters like genetic coefficient of variability (GCV), heritability $\left(h^{2}\right)$ and genetic advance (GA) were estimated (Al- 
Jibouri et al., 1958). Selection of $\mathrm{M}_{2}$ plants and $\mathrm{M}_{3}$ progenies were done on the basis of yield per plant. High yielding mutant cultures were identified in $\mathbf{M}_{4}$ generation on the basis of yield/plant.

\section{Results and Discussion}

To assess the nature and magnitude of induced polygenic variability of micro mutations in quantitative trait like yield/plant of the different mutagenic treatments, populations in $\mathrm{M}_{2}$ generation were analyzed through statistical parameters such as mean and variance. Analysis of variance of $\mathbf{M}_{2}$ population showed significant differences among the treatments for the above character in both the varieties.

The mutagen treated $\mathrm{M}_{2}$ populations showed varied extent of negative shift in mean of the character studied in both the varieties and the shift was significant in most cases (Table 1 and 2). However, the magnitude of shift in mean varied with the mutagens, their concentrations and parental genotypes. The negative shift of mean in $\mathrm{M}_{2}$ populations was more conspicuous in $\mathrm{MH}$ treatments for yield/plant in both the varieties. Similar differential negative shift of mean in different $\mathrm{M}_{2}$ populations were presented by Das and Misra (2005), Das et al., (2006), Khan et al., (2006), Lavanya et al., (2011) and Kozgar et al., (2011) in greengram. In most of the above reports, the shift of mean varied with mutagens and their doses. In this study, there was greater reduction of yield/plant in higher doses. Decrease in mean value at higher concentration may be due to shifting of mutagenic treatment mean to a direction opposite to selection. A comparative study of the effect of mutagens indicated that the negative shift of mean was more pronounced in $\mathrm{MH}$ and its combined treatments in both the varieties. This might be due to chromosomal abnormalities like stickiness, fragments, laggards, bridges etc. Das and Misra (2005) reported that comparatively lower magnitude of negative shift in gamma rays treatments might be due to less drastic effect and either induction of less number of micro mutants or induction of micro mutations in either direction. The negative shift could be attributed due to either physiological damage caused chiefly by chemical mutagens or chromosomal aberrations caused mainly by irradiations. Most of the mutagen treated $\mathrm{M}_{2}$ populations showed significant increase in population variance than control population for the character studied in both of the varieties (Table 1 and 2). However, the magnitude of increase in population variance varied with the mutagen, their concentration, parental genotypes and the character under consideration. The increase in variance of a $\mathrm{M}_{2}$ population in a trait is a general indicator of induction of micro mutation with negative and/or positive effect on the trait. Similar increase in variability in $\mathrm{M}_{2}$ population and differential increase in treatments with different mutagens, their combinations and doses in various growth and yield attributing traits in greengram had earlier been reported by Das and Misra (2005), Das et al., (2006), Khan et al., (2006), Wani and Khan (2006), Kumar et al., (2008) and Kozgar et al., (2011). The study showed that though dose-variance relationship was not completely linear, but in most of the cases higher doses of mutagens induced greater variance. These results are in agreement with earlier reports of Singh et al., (2001) and Sharma et al., (2008).

The $\mathrm{M}_{2}$ population variance per se does not give the true picture as it includes the genetic component of induced genetic variability due to mutagenic treatment (GCV) and environmental component of variability (ECV). Depending upon the magnitude of induced genetic variability in different treatment populations, the genetic parameters like GCV, heritability and genetic advance 
under selection would vary and these parameters can give an indication about effectiveness of mutagenic treatments for induction of micro mutations and scope of improvement for the trait through selection.

In the present investigation, the range, variance, GCV, heritability and genetic advance in $\mathrm{M}_{2}$ populations were estimated for yield/plant in both varieties (Table 1 and 2). Most of the mutagenic treatments induced wide range of variation in populations than their parental population. The range indicated that almost all mutagenic treatments induced wider range of variation in $\mathrm{M}_{2}$ populations in both directions for this character. The GCV estimates varied with mutagenic treatments and were high (13.70 - 41.38\%) for yield/plant in both varieties. Similar results for yield were also reported earlier by Singh et al., (2001), Sharma et al., (2008) and Kozgar et al., (2010, 2011). The heritability estimates for yield/plant in $\mathbf{M}_{2}$ populations varied with mutagens and their dose and in many cases it was relatively high (> 60\%) in both varieties, indicating greater scope of improvement through selection. Das et al., (2006), Mishra et al., (2008) and Sharma et al., (2008) have reported similar results in greengram. Genetic advance under selection (5\% intensity) in the $\mathrm{M}_{2}$ populations varied with treatments. The study revealed that selection in treated populations may lead to improvement of yield/plant up to $1.09 \mathrm{~g}$ in Sujata and $1.18 \mathrm{~g}$ in OBGG-52. Genetic advance as percentage of mean also increased in many treatments in both the varieties. Similar differential GA estimates in mutagenic populations for yield/plant in greengram were also reported by Das and Misra (2005) and Sharma et al., (2008). Simultaneous consideration of all genetic parameters in the different mutagenic treatment populations indicated that the treatments with sufficient genetic variability for yield/plant were G3, E2, N3, M1 and GN2 in Sujata and G3, E2, E3, N3 and M1 in OBGG-52. Thus, in general G3, E2, E3, N3,
M1 and GN2 treatments appeared to be effective for induction of micro mutation in yield and selection in $\mathrm{M}_{2}$ populations of these treatments would be effective in developing high yielding genotypes.

The scope of selection of micro mutants with improvement in desirable traits was generally determined by the magnitude and direction of induced polygenic variation in particular traits. Some earlier workers (Das et al., 2006; Sharma, 1986) selected $M_{2}$ families showing increase in variance with increase or no change in mean for the trait and were successful in not only reducing the bulk material from early generation, but also isolated several micro mutants in the later generations with improvement in the traits. With this rationale, both $\mathrm{M}_{2}$ population mean and variance were assessed simultaneously in the present study and the mutagenic treatments of the two varieties are presented in twodimensional graphs using $\mathbf{M}_{2}$ population mean and population variance of yield/plant (Fig. 1 and 2). Though most treatment populations showed reduction in mean and increase in variance in comparison to control, the $\mathrm{M}_{2}$ magnitude of such change varied with mutagens, their doses and the variety. The nature and magnitude of such changes may have bearing on the scope of improvement through selection. The significance of changes in mean and variance from the parental population for yield/plant was tested using $\mathrm{CD}$ at 5\% and classified using (i) parental (C) population mean - $\mathrm{CD}$ and (ii) parental (C) population variance $+\mathrm{CD}$. On this basis, the mutagen treated populations of both the varieties were classified into four groups: No significant decrease in mean without significant increase in variance (Group I) or with significant increase in variance (Group II) and significant decrease in mean with significant increase in variance (Group III) or with no significant increase in variance (Group IV). 
Table.1 Parameters of genetic variability for yield/plant in different mutagenic treatment in $\mathrm{M}_{2}$ generation of variety Sujata

\begin{tabular}{|c|c|c|c|c|c|c|c|c|}
\hline $\begin{array}{l}\text { Tr. } \\
\text { No. }\end{array}$ & Tr. Code & $\begin{array}{c}\text { Range } \\
\text { (g) }\end{array}$ & $\begin{array}{c}\text { Mean } \\
(\mathrm{g})\end{array}$ & Variance & $\begin{array}{l}\text { GCV } \\
(\%)\end{array}$ & $h^{2}(\%)$ & $\begin{array}{c}\text { GA }(5 \\
\%)\end{array}$ & $\begin{array}{c}\text { GA (\% of } \\
\text { Mean) }\end{array}$ \\
\hline 1 & G1 & $0.95-3.91$ & 2.05 & $0.51 *$ & 34.84 & 66.67 & 0.98 & 47.84 \\
\hline 2 & $\mathrm{G} 2$ & $0.71-3.64$ & 1.93 & $0.51 *$ & 38.52 & 70.18 & 1.09 & 55.68 \\
\hline 3 & G3 & $0.77-3.92$ & $1.85^{*}$ & $0.55^{*}$ & 39.72 & 68.52 & 1.04 & 56.07 \\
\hline 4 & E1 & $0.85-3.66$ & $1.89^{*}$ & $0.35 *$ & 29.13 & 43.33 & 0.49 & 26.01 \\
\hline 5 & E2 & $0.56-3.63$ & $1.73^{*}$ & $0.41 *$ & 38.34 & 61.36 & 0.84 & 48.47 \\
\hline 6 & E3 & $0.79-3.53$ & $1.63 *$ & $0.40 *$ & 37.04 & 52.78 & 0.65 & 40.27 \\
\hline 7 & N1 & $0.87-3.63$ & 1.96 & 0.23 & 23.50 & 19.05 & 0.18 & 9.22 \\
\hline 8 & N2 & $0.56-3.12$ & $1.77 *$ & 0.21 & 27.99 & 29.17 & 0.29 & 16.82 \\
\hline 9 & N3 & $0.87-3.78$ & $1.83^{*}$ & $0.34 *$ & 34.50 & 56.41 & 0.73 & 40.09 \\
\hline 10 & M1 & $0.65-3.64$ & $1.70 *$ & $0.33 *$ & 32.05 & 41.38 & 0.46 & 27.32 \\
\hline 11 & M2 & $0.30-2.20$ & $1.26^{*}$ & 0.20 & 35.49 & 15.00 & 0.14 & 10.97 \\
\hline 12 & M3 & $0.38-2.78$ & $1.16^{*}$ & 0.22 & 37.90 & 10.53 & 0.09 & 8.22 \\
\hline 13 & GE2 & $0.48-2.92$ & $1.45^{*}$ & $0.33 *$ & 41.38 & 52.78 & 0.65 & 44.99 \\
\hline 14 & GN2 & $0.89-3.60$ & $1.84 *$ & $0.38^{*}$ & 35.86 & 61.36 & 0.84 & 45.32 \\
\hline 15 & GM2 & $0.52-3.04$ & $1.52 *$ & 0.25 & 31.76 & 26.09 & 0.26 & 17.07 \\
\hline \multirow[t]{2}{*}{16} & Control & $1.42-2.74$ & 2.16 & 0.12 & & & & \\
\hline & $\mathrm{CD}(5 \%)$ & & 0.26 & 0.14 & & & & \\
\hline
\end{tabular}

* Significant decrease (mean) or increase (variance) over control at $5 \%$ level.

Table.2 Parameters of genetic variability for yield/plant in different mutagenic treatment in $\mathrm{M}_{2}$ generation of variety OBGG-52

\begin{tabular}{|c|c|c|c|c|c|c|c|c|}
\hline $\begin{array}{l}\text { Tr. } \\
\text { No. }\end{array}$ & Tr. Code & $\begin{array}{c}\text { Range } \\
\text { (g) }\end{array}$ & $\begin{array}{c}\text { Mean } \\
(\mathrm{g})\end{array}$ & Variance & $\begin{array}{c}\text { GCV } \\
(\%)\end{array}$ & $h^{2}(\%)$ & $\begin{array}{c}\text { GA }(5 \\
\%)\end{array}$ & $\begin{array}{c}\text { GA (\% of } \\
\text { Mean) }\end{array}$ \\
\hline 1 & G1 & $1.07-3.94$ & 2.16 & $0.36^{*}$ & 22.20 & 63.89 & 0.79 & 36.56 \\
\hline 2 & G2 & $1.22-3.82$ & 2.03 & $0.37 *$ & 24.13 & 64.86 & 0.81 & 40.04 \\
\hline 3 & G3 & $0.95-3.78$ & $1.93^{*}$ & $0.40 *$ & 26.92 & 67.50 & 0.88 & 45.57 \\
\hline 4 & E1 & $0.87-3.96$ & 2.02 & $0.35^{*}$ & 23.22 & 62.86 & 0.77 & 37.92 \\
\hline 5 & E2 & $0.84-3.61$ & 2.03 & $0.39 *$ & 25.12 & 66.67 & 0.86 & 42.25 \\
\hline 6 & E3 & $0.73-3.47$ & $1.58^{*}$ & $0.39 *$ & 32.27 & 66.67 & 0.86 & 54.28 \\
\hline 7 & N1 & $0.89-3.42$ & 2.01 & $0.37 *$ & 24.37 & 64.86 & 0.81 & 40.44 \\
\hline 8 & N2 & $0.87-3.76$ & $1.93 *$ & $0.51 *$ & 31.94 & 74.51 & 1.10 & 56.79 \\
\hline 9 & N3 & $0.79-4.09$ & $1.86^{*}$ & $0.56^{*}$ & 35.26 & 76.79 & 1.18 & 63.64 \\
\hline 10 & M1 & $1.02-4.16$ & $1.74 *$ & $0.35^{*}$ & 26.96 & 62.86 & 0.77 & 44.03 \\
\hline 11 & M2 & $0.62-3.16$ & $1.53^{*}$ & 0.23 & 20.67 & 43.48 & 0.43 & 28.07 \\
\hline 12 & M3 & $0.50-2.58$ & $1.35^{*}$ & 0.20 & 19.60 & 35.00 & 0.32 & 23.88 \\
\hline 13 & GE2 & $0.84-2.74$ & $1.46^{*}$ & 0.17 & 13.70 & 23.53 & 0.20 & 13.69 \\
\hline 14 & GN2 & $0.59-3.76$ & $1.48^{*}$ & 0.29 & 27.03 & 55.17 & 0.61 & 41.35 \\
\hline 15 & GM2 & $0.57-3.64$ & $1.37 *$ & 0.23 & 23.08 & 43.48 & 0.43 & 31.35 \\
\hline \multirow[t]{2}{*}{16} & Control & $1.55-2.85$ & 2.33 & 0.13 & & & & \\
\hline & $\mathrm{CD}(5 \%)$ & & 0.33 & 0.17 & & & & \\
\hline
\end{tabular}

* Significant decrease (mean) or increase (variance) over control at $5 \%$ level. 
Table.3 Classification of mutagenic treatments based on $\mathrm{M}_{2}$ mean and variance for yield/plant and frequency of high yielding mutants obtained from them in $\mathrm{M}_{4}$ generations

\begin{tabular}{|c|c|c|c|}
\hline \multirow{2}{*}{$\begin{array}{c}\text { Mutagenic } \\
\text { treatment } \\
\text { group in } \mathbf{M}_{2}\end{array}$} & \multirow[t]{2}{*}{ Mutagenic treatments } & \multicolumn{2}{|c|}{$\begin{array}{l}\text { High yielding mutant progenies/cultures } \\
\qquad \mathrm{M}_{4}\end{array}$} \\
\hline & & No. & $\%$ \\
\hline \multicolumn{4}{|l|}{ SUJATA } \\
\hline Group I & N1 & 1 & 10.0 \\
\hline Group II & $\mathrm{G} 1, \mathrm{G} 2$ & 2 & 20.0 \\
\hline Group III & G3, E1, E2, E3, N3, M1, GE2, GN2 & 7 & 70.0 \\
\hline \multirow[t]{2}{*}{ Group IV } & $\mathrm{N} 2, \mathrm{M} 2, \mathrm{M} 3, \mathrm{GM} 2$ & 0 & 0.0 \\
\hline & Total & 10 & \\
\hline \multicolumn{4}{|l|}{$O B G G-52$} \\
\hline Group I & - & 0 & 0.0 \\
\hline Group II & $\mathrm{G} 1, \mathrm{G} 2, \mathrm{E} 1, \mathrm{E} 2, \mathrm{~N} 1$ & 3 & 27.3 \\
\hline Group III & $\mathrm{G} 3, \mathrm{E} 3, \mathrm{~N} 2, \mathrm{~N} 3, \mathrm{M} 1$ & 6 & 54.5 \\
\hline \multirow[t]{2}{*}{ Group IV } & M2, M3,GE2, GN2, GM2 & 2 & 18.2 \\
\hline & Total & 11 & \\
\hline
\end{tabular}

Fig.1 Scatter diagram of the treatments in Sujata with respect to mean and variance in $\mathrm{M}_{2}$ generation

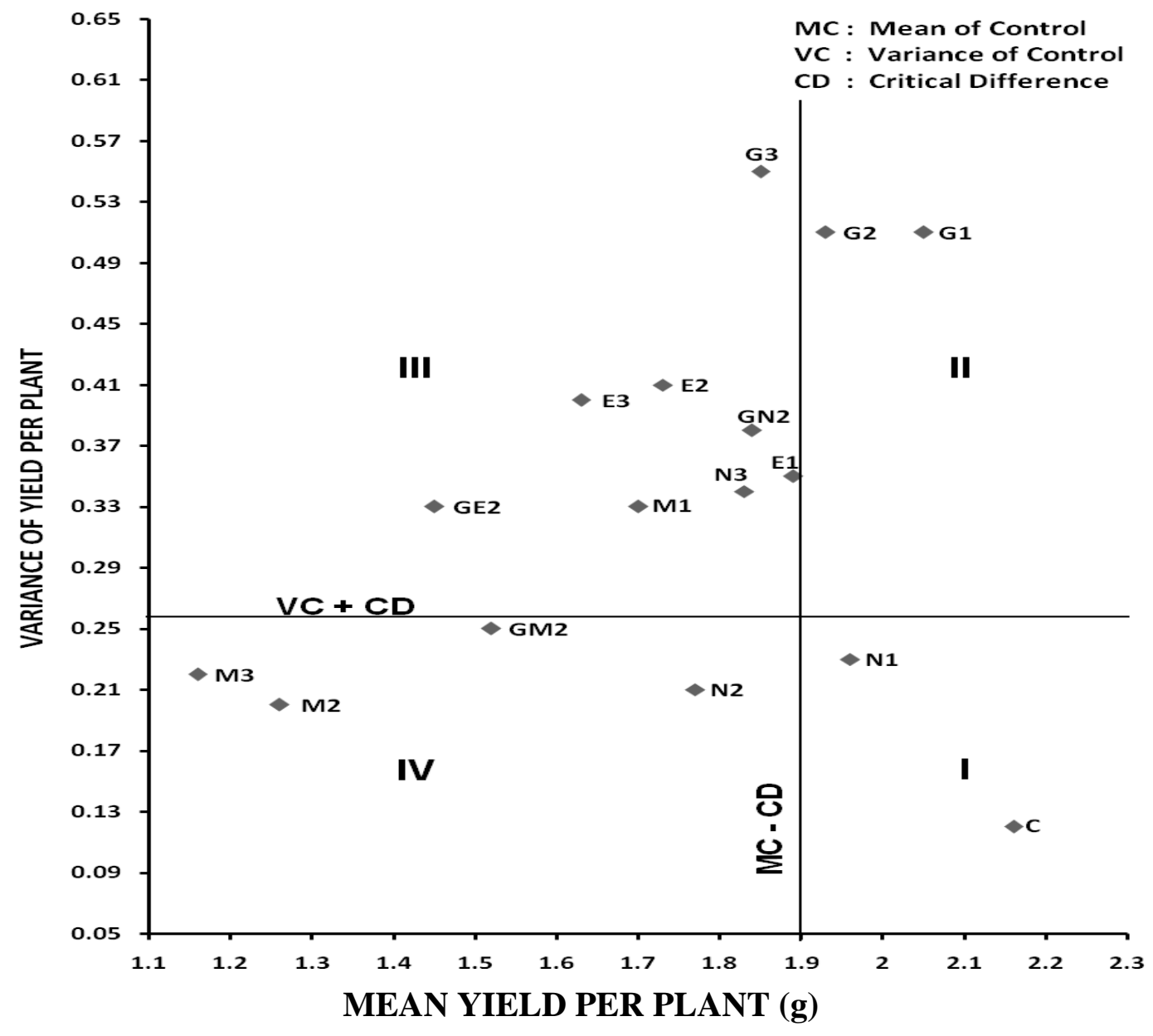


Fig.2 Scatter diagram of the treatments in OBGG 52with respect to mean and variance in $\mathrm{M}_{2}$ generation

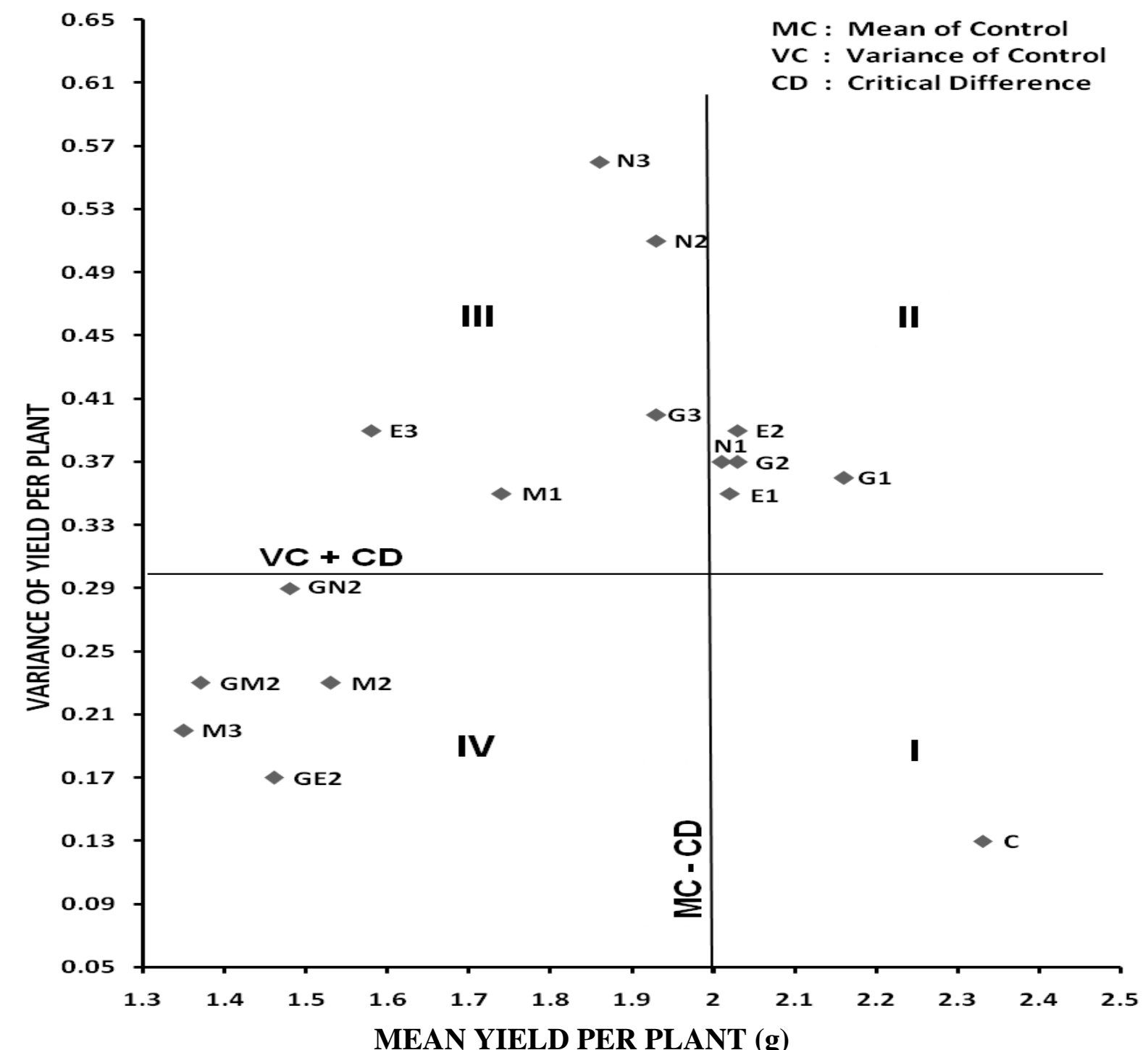

The Group I mutagenic treatment (only N1 of Sujata) showing no significant decrease in mean and no significant increase in variance were supposed to possess very little induction of micro mutations in yield. Thus, selection from these treatments was expected to have very little success. The study also revealed that only one high yielding $\mathrm{M}_{4}$ progenies in Sujata and no high yielding mutant culture in OBGG-52 were obtained from this group of treatments. The frequency of superior mutant progenies with higher yield than the parent variety obtained in $\mathrm{M}_{3}$ and significantly higher yielding genotypes in $\mathrm{M}_{4}$ generations from different $M_{2}$ mutagenic treatment groups are given in Table 3 .

The Group II showing significant increase in population variance for yield/plant without any significant decrease in treatment means included G1 and G2 treatments in case of Sujata and G1, G2, E1, E2 and N1 in case of OBGG-52. This indicated that induction of micro mutation for yield in these treatments 
was random and in both positive and negative directions. The high yielding mutant progenies identified from this group of treatments in $\mathrm{M}_{4}$ generations were $20 \%$ in case of Sujata while $25 \%$ in case of OBGG52 , respectively. Thus, the expectation of isolating more high yielding micro mutants through selection from these treatments seems correct. Similar success in micro mutational improvement through selection in $\mathbf{M}_{2}$ families showing increased variability without decrease in mean with respect to parent and further selection of plants or lines have been reported earlier by Das et al., (2006). In both the varieties, selection of $\mathrm{M}_{2}$ plants and $\mathrm{M}_{3}$ progenies in Group II mutagenic treatments was most effective in isolation of high yielding mutants in $\mathrm{M}_{4}$ generation.

The Group III treatments (G3, E1, E2, E3, N3, M1, GE2, GN2 of Sujata and G3, E3, N2, N3, M1 of OBGG-52) showing significant increase in variance with significant decrease in mean were supposed to have more plants with induction of micro mutations having negative effects and relatively small proportion of plants with negative effects. Thus, induction of micromutation for yield in this group appeared to be more frequent in the opposite direction of previous selection history of the parental genotype and less in positive direction. In spite of that, adoption of proper selection procedure may useful in identification of relatively good number of high yielding mutants from these treatments. In the present study, this group produced reasonably large portion of high yielding $\mathrm{M}_{4}$ cultures $(70.0 \%)$ in Sujata and OBGG-52 $(54.5 \%)$ indicating that selection in these treatments was effective in isolation of high yielding mutants.

The Group IV (N2, M2, M3, GM2 treatments of Sujata and M2, M3, GE2, GN2, GM2 of OBGG-52) showing significant decrease in mean without significant increase in variance would indicate that induction of micro mutation might be non-random, mostly in negative direction. Induction of such micro mutations only with negative effect is generally rare, particularly in yield. The scope of improvement through selection from this group would be quite restricted.

In the present study, out of the fifteen $\mathrm{M}_{2}$ mutagenic treatment populations of both varieties only eight treatment in each (G1, G3, E1, E2, E3, N1, N3 and M1 in Sujata and G1, G3, E1, E2, N3, M1, M2 and GN2 in OBGG52) showed significant increase for yield over control and 18 out of the 21 significantly high yielding cultures identified in $\mathrm{M}_{4}$ were from the group having significant increase in variance i.e. group-II and III. Thus, it can be inferred that selection of high yielding $\mathrm{M}_{2}$ plants in those mutagenic treatments showing increased $\mathrm{M}_{2}$ population variance with significant increase or decrease in mean value for yield would be effective in isolation of high yielding micro mutants. This early prediction selection method can be very useful in isolation for promising mutants in early generation ultimately save the resources.

\section{References}

Al-Jibouri H. A., Miller P. A. and Rabinson H. F. 1958. Genotypic and environmental variances and co-variances in upland cotton crosses of inter-specific origin. Agron. Jr., 50: 633-636.

Anonymous. 2016. PC AICRP- MULLaRP (Mungbean) report, IIPR, Kanpur. pp:29

Chattopadhyay K., Sarakar H. K. and Bhattacharyya S. 2011. Estimation of genetic distances based on agro morphological and molecular/ parameters in mungbean - a case study. Jr. Food Legumes. 24(4): 277-281.

Das T. R. and Misra R. C. 2005. Genetic analysis of mutagen induced variability in 
yield traits in greengram (Vigna radiata). Environment and Ecology, 23: 381-384.

Das T. R., Misra R. C. and Sahu P. K. 2006. Efficiency of mutagenic treatments in expression of macro and micro mutations in $\mathrm{M}_{2}$ generation in greengram and its early predictability on basis of $\mathrm{M}_{1}$ parameters. Environment and Ecology, 24: 283-288.

Das, S., Das, S.S. and Ghosh, P. 2014. A comparative analysis of genetic diversity across certain mung bean and urd bean cultivars of West Bengal, using ISSR markers. Asian J. Plant Sci. Res., 4: 56 - 61.

Dhoot R., Modha K.G., Kumar D and Dhoot M. 2017. Correlations and Path Analysis Studies on Yield and its Components in Mungbean (Vigna radiata (L.) Wilczek). Int.J.Curr.Microbiol.App.Sci. 6(5): 370378

Directorate of Economics and statistics (DES), 2016.// eands.dacnet.nic.in

Khan S., Wani M. R. and Praveen K. 2006. Quantitative variability in mungbean induced by chemical mutagens. Legume Res., 29(2): 143-145.

Kozgar M. I., Goyal S. and Khan S. 2010. EMS induced mutational variability in Vigna radiata and Vigna mungo. Res. J. Botany, 1: 1-7.

Kozgar M. I., Goyal S. and Khan S. 2011. EMS induced mutational variability in Vigna radiata and $V$. mungo. Res. J. Botany, 6: 31-37.

Kumar A., Parmhansh P., Kumar R. and Prasad
R. 2008. Induced genetic variability for quantitative characters in mungbean (Vigna radiata L. Wilczek). Indian Agric., 52: 93-98.

Lavanya G. R., Yadav L., Babu G. S. and Paul P. J. 2011. Sodium azide mutagenic effect on biological parameters and induced genetic variability in mungbean. Jr. Food Legume, 24: 46-49.

Mishra L. D., Baisakh B. and Nayak P. K. 2008. Genetic variability among advanced mutant lines of mungbean. $J r$. Food Legumes, 21: 274-275.

Shanmugasundaram S. 2001. New breakthrough with green gram. Centerpoint 19: 1-2.

Sharma V., Kumar G. and Kuamr R. 2008. EMS induced polygenic variations in mungbean. Jr. Food Legumes, 21: 61-62.

Sharma B. 1986. Increasing the efficiency of mutagenesis for micro mutations by early generation selection. Indian $J$. Genet., 46(Suppl.): 88-100

Singh G., Sareen P. K., Saharan R. P. and Singh A. 2001. Induced variability in mungbean ( $V$. radiata (L.) Wilczek). Indian $J$. Genet., 61: 281-282.

Singh N, Singh H, Nagarajan P., 2013. Development of SSR markers in mung bean, Vigna radiata (L.) Wilczek using in silico methods. J Crop Weed 9: 6974.

Wani M. R. and Khan S. 2006. Estimates of genetic variability in mutated populations and the scope of selection for yield attributes in Vigna radiata (L.) Wilczek. Egyptian Journal of Biology, 8: 1-6.

\section{How to cite this article:}

Tapas Ranjan Das and Bhabendra Baisakh. 2018. Mutation-induced Polygenic Variability and Early Prediction of High Yielding Mutants in Greengram [Vigna radiata (L.) wilczek]. Int.J.Curr.Microbiol.App.Sci. 7(01): 3228-3236. doi: https://doi.org/10.20546/ijcmas.2018.701.386 